\title{
Veteran Preferences Regarding Wireless Management of Positive Airway Pressure for Obstructive Sleep Apnea at a Tertiary Health-Care System
}

\author{
Ken He MD, Brian N Palen MD, Elizabeth A Mattox MSN MSc, and \\ Elizabeth C Parsons MD MSc
}

\begin{abstract}
BACKGROUND: Timely monitoring of obstructive sleep apnea (OSA) therapy can be a challenge amid conflicting pressures of rising patient volume and shortage of sleep medicine providers. Positive airway pressure (PAP) devices with wireless modem technology have the potential to improve patient access to care and streamline work load, yet little is known about patient attitudes toward telehealth integration among veterans with sleep apnea. As part of a larger quality improvement initiative at the Veterans Affairs (VA) Puget Sound Health Care System, we elicited veterans' preferences toward modem versus traditional PAP data download, including patient attitudes and factors affecting those preferences. METHODS: We conducted an anonymous survey of veterans without previous CPAP experience presenting for initial device setup and training at VA Puget Sound PAP clinics. Surveys assessed subject demographics, PAP download preferences (modem vs mail), and Likert-type scale ratings of importance placed on factors including convenience and information privacy. Using multinomial logistic regression, we examined the association between convenience rating and download preference, adjusting for information privacy rating, age, and commute time. RESULTS: Of $\mathbf{4 4 4}$ surveys analyzed, respondents were primarily male with a mean age of $52 \mathrm{y}$. Most respondents reported taking $\geq 30 \mathrm{~min}$ to commute to the PAP clinic. Convenience was rated as the most important factor affecting download preferences. Veteran preferences regarding PAP download method were mixed, with $47 \%$ preferring modem, $38 \%$ preferring memory card mail-in, and $15 \%$ undecided. A higher rating of convenience was significantly associated with modem preference, both before and after adjustment for information privacy rating, commute time, and veteran age (adjusted relative risk ratio $1.67, P<.001,95 \%$ CI 1.40-1.99). CONCLUSIONS: PAP data download preferences were mixed among new veteran users. Veterans placed a high value on the potentially competing concerns of convenience and information privacy. Veterans preferring modem factored convenience as important in their decision making, independent of privacy concerns. Key words: sleep apnea syndrome; CPAP; patient preference; telehealth; telemedicine; e-health; home health monitoring; technology. [Respir Care 2017;62(3):357-362. ( 2017 Daedalus Enterprises]
\end{abstract}

Introduction

Obstructive sleep apnea (OSA) affects up to $26 \%$ of adults, with negative consequences including quality of

Drs Palen and Parsons are affiliated with the Division of Pulmonary and Critical Care Medicine, University of Washington, Seattle, Washington. Dr He, Dr Palen, Ms Mattox, and Dr Parsons are affiliated with the Veterans Affairs Puget Sound Health Care System, Seattle, Washington.

The authors have disclosed no conflicts of interest. life impairment, work productivity loss, motor vehicle accidents, and cardiovascular risk. ${ }^{1,2}$ Treatment of OSA with positive airway pressure (PAP) can improve insomnia, reduce cardiovascular risk, and potentially improve posttraumatic stress disorder symptoms..$^{3-7}$ Optimal OSA manage-

\footnotetext{
Drs He and Palen contributed equally to this work.

Supplementary material related to this paper is available at http:// www.rcjournal.com.
} 
ment requires timely follow-up to monitor therapy efficacy by a sleep specialist at an accredited sleep center. ${ }^{8-10}$ OSA care is a growing need among veterans. ${ }^{11-13}$ Veterans utilizing the Department of Veterans Affairs (VA) Veterans Health Administration (VHA) system for OSA care may experience barriers due to sleep medicine provider shortage and concentration of specialty services at mostly metropolitan, tertiary care centers. ${ }^{14-17}$ Rural veterans are particularly vulnerable to follow-up attrition or fragmented care, ${ }^{18}$ yet they represent approximately $43 \%$ of the 19.4 million United States veterans served by the VHA system. ${ }^{19}$

Monitoring of PAP data download by wireless modem is an emergent telehealth technology that allows for remote, real-time, even nightly therapy assessment and adjustment without an in-person visit. ${ }^{20}$ Telehealth strategies incorporating wireless PAP download may promote early PAP adherence ${ }^{21}$ and improve sleep-related functional outcomes. ${ }^{22-27}$ Patient satisfaction with telehealth formats is high, with patients citing increased convenience, therapy feedback, and accountability. ${ }^{28-30}$ The VHA is a leader in telehealth utilization to improve care coordination, especially among rural veterans, ${ }^{31-35}$ yet PAP modem download is a relatively new development that has not yet reached widespread implementation in most VA health systems.

Recent publications in civilian populations suggest that modem download provides equivalent or greater PAP adherence and greater patient satisfaction compared with usual care. $24,36,37$ However, VHA-enrolled veterans differ from the civilian population in ways that may impact their attitudes and preferences regarding sleep care. Compared with the general United States population, VHA-enrolled veterans are more likely to be male, white non-Hispanic, and are on average older with higher personal incomes. ${ }^{19,38,39}$ Such factors may impact veteran attitudes toward telehealth strategies. Two small pilot studies have demonstrated that institution of PAP modem monitoring is feasible among veterans and is associated with high patient satisfaction and adherence, ${ }^{28,30}$ yet to our knowledge, there are no data specifically eliciting whether most veterans prefer remote monitoring nor identifying subgroups of veterans who might still prefer or benefit from conventional follow-up.

Similar to national trends, OSA care is a growing need at the VA Puget Sound, with sleep medicine referrals at our facility increasing by $20 \%$ each year over the past

\footnotetext{
Correspondence: Elizabeth Parsons MD MSc, VA Puget Sound Health Care System, 1600 S Columbian Way, S-111 Pulm, Seattle, WA 98108. E-mail: Elizabeth.parsons@va.gov.
}

DOI: $10.4187 /$ respcare. 05002

\section{QUICK LOOK}

\section{Current knowledge}

Sleep apnea is very common, particularly among veterans, creating a challenge to meet growing patient demand despite a general shortage of sleep medicine providers. Optimal sleep apnea care includes positive airway pressure (PAP) device monitoring and adjustment to ensure adequate therapy. PAP modem download offers the potential to streamline care and improve access, yet little is known about veteran preferences toward telehealth technology or what factors veterans consider important when integrating technology into patient-centered care initiatives.

\section{What this paper contributes to our knowledge}

At a tertiary care veterans administration health center, PAP data download preferences were mixed among new veteran users. Veterans considered convenience, information privacy, and provider recommendation as factors important to their decision making.

5 years. VA Puget Sound has an estimated 20,000 veterans enrolled in our CPAP clinic, which conducts approximately 3,000 visits/y. To better serve a growing population with a significant number of rural veterans, in 2015 we sought to evaluate the introduction of wireless PAP download into our current care practice.

We surveyed veterans presenting for initial CPAP setup to elicit preferences regarding modem versus conventional in-clinic PAP download. At a broader quality improvement level, we sought to examine patient factors that might impact care preferences and attitudes, with the goal of identifying the veteran groups most likely to prefer telehealth CPAP management.

\section{Methods}

\section{Study Population}

The VA Puget Sound is part of the VA Northwest Health Network serving veterans in Washington, Alaska, Oregon, Idaho, Montana, and California. It is the largest VA health network geographically, serving $>89,000$ veterans at 7 clinical sites. ${ }^{40}$ Approximately $41 \%$ of veterans receiving care within the VA Northwest Health Network reside in rural areas..$^{40}$ Veterans receiving care at VA Puget Sound are representative of the VHA-served veteran population at large. National and Washington State data reveal that veterans are predominately male (approximately 90\%) and white non-Hispanic, have a median age of $64 \mathrm{y}$, and are 


\section{PAP Follow-Up Preferences Among Veterans}

more likely to work in management and professional occupations compared with their civilian counterparts. ${ }^{19}$

At VA Puget Sound, sleep evaluation is initiated by a sleep consultation placed by a referring provider into the electronic medical record. A sleep medicine provider then reviews the consultation request and orders the appropriate evaluation. Veterans meeting OSA treatment criteria by current American Academy of Sleep Medicine guidelines are evaluated in one of 2 PAP clinics located approximately 40 miles apart, for initial PAP device setup, education, and training. Patients receive a self-addressed envelope with instructions to mail their device memory card within 1 month for data download to assess adherence and treatment efficacy.

\section{Data Collection}

This survey was performed as part of an ongoing quality improvement project with a goal of incorporating telehealth strategies to streamline care and improve access. With the recent advent of PAP modem technology at our facility, we sought to elicit subject preferences to best guide our implementation of this technology. We conducted an anonymous survey on veterans presenting for initial device setup and training to the 2 VA PAP clinics between December 19, 2014 and July 9, 2015. Written surveys (see the supplementary materials at http://www. rcjournal.com) were administered at the beginning of the visit with instructions to minimize potential bias.

The survey assessed subject demographics (sex, age, self-reported commute time to the PAP clinic); download preference (modem, mail-in memory card, or undecided); and factors affecting download preference decision making, such as convenience, information privacy, provider preference, recommendations from other persons, and other stated reasons (Likert-type scale of 1 [not at all important] to 7 [extremely important]). This survey was voluntary and anonymous and was performed under the auspices of quality improvement, in accordance with procedures set forth in VHA Handbook 1058.05. Institutional review board approval was therefore not required.

\section{Statistical Analyses}

All analyses were performed using Stata/MP version 13.1. We performed descriptive analysis of sex, age, commute times, ratings of decision factors ("other category" was not included due to minimal responses), and follow-up preferences (responses assigned as undecided if no preference or both modem and mail-in were selected). We performed unadjusted multinomial logistic regression examining the association between ratings of convenience and wireless modem preference. We then repeated the analysis adjusting for a priori potential confounders of
Table 1. Veteran Descriptives

\begin{tabular}{lc}
\hline \hline \multicolumn{1}{c}{ Characteristics } & Values \\
\hline Demographics & \\
Age, mean \pm SD (range) y & $52 \pm 14(20-92)$ \\
Male sex, $n(\%)$ & $404(91)$ \\
Commute time (min), $n(\%)$ & \\
$\quad<30$ & $113(25)$ \\
$\quad 30-60$ & $189(43)$ \\
$\quad>60$ & $142(32)$ \\
Importance in decision-making, median & \\
$\quad$ interquartile range)* & \\
Convenience & $6(2)$ \\
Information privacy & $5(3)$ \\
Provider preference & $5(2)$ \\
Recommendation by other persons & $4(2)$ \\
PAP download preference, $n(\%)$ & \\
$\quad$ Modem & $209(47)$ \\
Mail-in & $170(38)$ \\
Undecided & $65(15)$ \\
\hline$N=444$. & \\
$*$ Scale from 1 (not at all important) to 7 (extremely important). & \\
\end{tabular}

information privacy rating, age, and commute time. We did not adjust analyses for sex due to the limited number of female respondents.

\section{Results}

\section{Demographics}

A total of 491 surveys were returned. Of these, 444 veterans completed all survey items for inclusion in the analyses (Table 1). Respondents were primarily male (91\%) with a mean age of 52 y (range 20-92 y). Self-reported commute times from the veterans' residence to the VA PAP clinic were $<30 \min (25 \%), 30-60 \min (43 \%)$, and $>60$ min $(32 \%)$.

\section{Veteran Preferences and Factors Affecting Decision Making}

When asked their preferred mode of PAP download, $47 \%$ of veterans preferred modem, $38 \%$ preferred memory card mail-in, and $15 \%$ were undecided, with notable comments of "prefer the method that works the best," "don't know how it works," and "modem if no security issues" among others. When asked about factors affecting their decisions with respect to download preference, veterans rated convenience the highest (median rating "very important"), followed by information privacy (median rating "moderately important") and provider preference (median rating "moderately important"). 
Table 2. Association Between Download Preferences and Veteran Factors/Demographics

\begin{tabular}{lcc}
\hline $\begin{array}{c}\text { Subject } \\
\text { Factors/Demographics }\end{array}$ & $\begin{array}{c}\text { Unadjusted RRR } \\
(P, 95 \% \mathrm{CI}) *\end{array}$ & $\begin{array}{c}\text { Adjusted RRR } \\
(P, 95 \% \mathrm{CI}) * \dagger\end{array}$ \\
\hline $\begin{array}{l}\text { Rating of convenience } \\
\text { Prefers modem }\end{array}$ & $1.56(<.001,1.32-1.84)$ & $1.67(<.001,1.40-1.99)$ \\
$\quad \begin{array}{l}\text { Undecided } \\
\text { Rating of information } \\
\text { privacy }\end{array}$ & $1.03(.76,0.86-1.24)$ & $1.04(.70,0.85-1.26)$ \\
$\quad \begin{array}{l}\text { Prefers modem } \\
\text { Undecided }\end{array}$ & $0.96(.40,0.87-1.06)$ & $0.87(.01,0.78-0.97)$ \\
Age & $0.99(.88,0.86-1.14)$ & $0.98(.77,0.84-1.14)$ \\
$\quad$ Prefers modem & $0.98(.03,0.97-1.00)$ & $0.98(.01,0.96-0.99)$ \\
$\quad$ Undecided & $1.00(.86,0.98-1.02)$ & $1.00(.95,0.98-1.02)$ \\
Commute time & $1.11(.43,0.85-1.46)$ & $1.21(.19,0.91-1.62)$ \\
$\quad \begin{array}{l}\text { Prefers modem } \\
\text { Undecided }\end{array}$ & $1.09(.67,0.74-1.59)$ & $1.09(.68,0.74-1.60)$ \\
&
\end{tabular}

\section{Association Between Preference and Veteran Factors}

For unadjusted multinomial logistic regression, higher rating of convenience was associated with higher likelihood of modem download preference (relative risk ratio [RRR] 1.56, $P<.001,95 \%$ CI 1.32-1.84, with mail-in method as the baseline outcome) (Table 2). This association remained statistically significant after adjusting for potential confounders, including information privacy rating, commute time, and veteran age (RRR 1.67, $P<.001$, 95\% CI 1.40-1.99).

In secondary analyses, modem download preference was negatively associated with higher information privacy rating (adjusted $P=.01,95 \%$ CI $0.78-0.97$ ) and increasing age (adjusted $P=.01,95 \%$ CI $0.96-0.99$ ). There was no significant association between download preference and commute time.

\section{Discussion}

In this quality improvement project at a tertiary care VA health-care system, PAP download preferences were mixed among new PAP users, with the highest percentage (47\%) preferring modem. Veterans rating convenience highly were more likely to prefer modem, an association that remained statistically significant after adjustment for subject age, commute time, and information privacy rating. Older veterans and those who rated information privacy highly were less likely to prefer modem download. Our results may be compared with a prior survey of civilian subjects at a tertiary care sleep clinic, in which most subjects reported comfort and willingness to try a new method of video communication despite lack of prior experience. ${ }^{41}$
In contrast to our findings, the authors did not find a relationship between age and subject comfort with telehealth. ${ }^{41}$

Two prior publications have demonstrated feasibility of telehealth strategies in veterans with OSA. ${ }^{28,30}$ Stepnowsky et $\mathrm{al}^{30}$ compared daily PAP data transmission by wireless modem with usual OSA care among 45 veterans followed for 2 months, showing a trend toward greater adherence in the telehealth group. The accuracy of wireless transmissions was $100 \%$ with a very low rate of transmission failures in all subjects. Neither the modem nor usual care group reported significant privacy concerns about being remotely monitored. Fields et al ${ }^{28}$ compared real-time video interviews with usual care for follow-up OSA care in 60 veterans with interval data download by PAP wireless modem in all subjects. They found greater improvement in mental health scores at 3 months and subject satisfaction in the telehealth group.

Our findings add to the existing literature ${ }^{28,30}$ by highlighting that veteran receptivity to sleep telehealth strategies may be complex and related to a variety of potentially competing factors. We identified convenience as an important aspect of veterans' perceptions of care quality. Unlike Stepnowsky et al, ${ }^{30}$ we found that veterans with concerns about monitoring or information privacy were actually less likely to prefer modem download. A few participants in the studies by Fields et al ${ }^{28}$ and Smith et al ${ }^{23}$ noted concerns related to confidentiality and intrusion of privacy. Our project's strengths include a large sample size without exclusionary criteria and eliciting early participant attitudes about their care preferences before introduction of the technology to help identify potential knowledge gaps. Surveys were anonymous with minimal guidance from PAP clinic staff to maximize patient confidentiality and minimize bias of responses.

Surprisingly, we did not find a strong relationship between commute time and preferred PAP download method, although we found a trend toward modem preference (not statistically significant). These findings may be explained by the lack of inherent impact of travel time to our VA PAP clinics between modem and mail-in strategies (inperson follow-up was not explicitly compared). The Michael E. Debakey VA Medical Center (Houston, Texas) instituted remote sleep medicine services at communitybased out-patient clinics, which generated positive responses from geographically distanced veterans not having to visit the main medical center. ${ }^{42}$

Our results must be interpreted in the context of several limitations. First, this was a voluntary, quality improvement survey of mostly male veterans who chose to participate during an initial visit to VA PAP clinics. Our results may not reflect the views of veterans who chose not to complete the survey or obtained OSA care in the community. Second, our survey assessed veteran preferences re- 


\section{PAP Follow-Up Preferences Among Veterans}

garding download at initial setup, a time when veterans may not be knowledgeable about PAP devices. Experienced users might have different preferences and concerns. Last, our aim was to solicit unbiased veteran preferences regarding their care. Surveys were therefore entirely anonymous and could not be linked to disease severity or outcomes, such as treatment adherence. We obtained demographics and commute time entirely by veteran self-report.

We believe that incorporation of PAP data download by modem and other telehealth strategies for interested veterans will improve OSA care quality for veterans at VA Puget Sound, redirecting limited resources to patients who require more assistance or prefer traditional methods of care. Unanswered questions remain as to how best to merge telehealth and traditional health to address potentially competing concerns of information privacy and convenience. There is a clear need to establish standardized protocols regarding how, when, and who should be monitoring these wireless data transmissions; safeguards to data loss; and how to incorporate patients residing in rural locations outside of wireless network zones. ${ }^{43}$

\section{REFERENCES}

1. Young T, Peppard PE, Gottlieb DJ. Epidemiology of obstructive sleep apnea: a population health perspective. Am J Respir Crit Care Med 2002;165(9):1217-1239.

2. Peppard PE, Young T, Barnet JH, Palta M, Hagen EW, Hla KM. Increased prevalence of sleep-disordered breathing in adults. Am J Epidemiol 2013;177(9):1006-1014.

3. Krakow B, Lowry C, Germain A, Gaddy L, Hollifield M, Koss M, et al. A retrospective study on improvements in nightmares and post-traumatic stress disorder following treatment for co-morbid sleep-disordered breathing. J Psychosom Res 2000;49(5):291-298.

4. Björnsdóttir E, Janson C, Sigurdsson JF, Gehrman P, Perlis M, Juliusson $\mathrm{S}$, et al. Symptoms of insomnia among patients with obstructive sleep apnea before and after two years of positive airway pressure treatment. Sleep 2013;36(12):1901-1909.

5. Nishihata Y, Takata Y, Usui Y, Kato K, Yamaguchi T, Shiina K, Yamashina A. Continuous positive airway pressure treatment improves cardiovascular outcomes in elderly patients with cardiovascular disease and obstructive sleep apnea. Heart Vessels 2015;30(1): 61-69.

6. Rivas M, Ratra A, Nugent K. Obstructive sleep apnea and its effects on cardiovascular diseases: a narrative review. Anatol J Cardiol 2015; 15(11):944-950.

7. Sánchez-de-la-Torre M, Campos-Rodriguez F, Barbé F. Obstructive sleep apnoea and cardiovascular disease. Lancet Respir Med 2013; 1(1):61-72.

8. Epstein LJ, Kristo D, Strollo PJ, Jr., Friedman N, Malhotra A, Patil $\mathrm{SP}$, et al. Clinical guideline for the evaluation, management and long-term care of obstructive sleep apnea in adults. J Clin Sleep Med 2009;5(3):263-276

9. Hossain JL, Shapiro CM. The prevalence, cost implications, and management of sleep disorders: an overview. Sleep Breath 2002; $6(2): 85-102$

10. Phillips B, Gozal D, Malhotra A. What is the future of sleep medicine in the United States? Am J Respir Crit Care Med 2015;192(8): 915-917.
11. Ocasio-Tascón ME, Alicea-Colón E, Torres-Palacios A, RodríguezCintrón W. The veteran population: one at high risk for sleepdisordered breathing. Sleep Breath 2006;10(2):70-75.

12. Mustafa M, Erokwu N, Ebose I, Strohl K. Sleep problems and the risk for sleep disorders in an outpatient veteran population. Sleep Breath 2005;9(2):57-63.

13. Sharafkhaneh A, Richardson P, Hirshkowitz M. Sleep apnea in a high risk population: a study of Veterans Health Administration beneficiaries. Sleep Med 2004;5(4):345-350.

14. Bradley TD, Rutherford R, Grossman RF, Lue F, Zamel N, Moldofsky H, Phillipson EA. Role of daytime hypoxemia in the pathogenesis of right heart failure in the obstructive sleep apnea syndrome. Am Rev Respir Dis 1985;131(6):835-839.

15. Sarmiento K, Rossettie J, Stepnowsky C, Atwood C, Calvitti A, VA Sleep Network. The state of Veterans Affairs sleep medicine programs: 2012 inventory results. Sleep Breath 2016;20(1):379-382.

16. Flemons WW, Douglas NJ, Kuna ST, Rodenstein DO, Wheatley J. Access to diagnosis and treatment of patients with suspected sleep apnea. Am J Respir Crit Care Med 2004;169(6):668-672.

17. Cotton HR and Altevogt BM, Committee on Sleep Medicine and Research, Board on Health Sciences Policy, Institute of Medicine. Sleep disorders and sleep deprivation: an unmet public health problem. Washington, DC: The National Academies Press; 2006:217220.

18. Friedman SA, Frayne SM, Berg E, Hamilton AB, Washington DL, Saechao F, et al. Travel time and attrition from VHA care among women veterans: how far is too far? Med Care 2015;53(4 Suppl 1):S15-S22.

19. National Center for Veterans Analysis and Statistics. Unique Veterans Users Report FY 2014. http://www.va.gov/vetdata/docs/SpecialReports/ Profile_of_Unique_Veteran_Users_2014.pdf. Accessed September 13, 2016.

20. Lankford DA. Wireless CPAP patient monitoring: accuracy study. Telemed J E Health 2004;10(2):162-169.

21. Budhiraja R, Parthasarathy S, Drake CL, Roth T, Sharief I, Budhiraja $\mathrm{P}$, et al. Early CPAP use identifies subsequent adherence to CPAP therapy. Sleep 2007;30(3):320-324

22. Isetta V, Negrín MA, Monasterio C, Masa JF, Feu N, Álvarez A, et al. A Bayesian cost-effectiveness analysis of a telemedicine-based strategy for the management of sleep apnoea: a multicentre randomised controlled trial. Thorax 2015;70(11):1054-1061.

23. Smith CE, Dauz ER, Clements F, Puno FN, Cook D, Doolittle G, Leeds W. Telehealth services to improve nonadherence: a placebocontrolled study. Telemed J E Health 2006;12(3):289-296.

24. Kuna ST, Shuttleworth D, Chi L, Schutte-Rodin S, Friedman E, Guo $\mathrm{H}$, et al. Web-based access to positive airway pressure usage with or without an initial financial incentive improves treatment use in patients with obstructive sleep apnea. Sleep 2015;38(8):1229-1236.

25. DeMolles DA, Sparrow D, Gottlieb DJ, Friedman R. A pilot trial of a telecommunications system in sleep apnea management. Med Care 2004;42(8):764-769.

26. Fox N, Hirsch-Allen AJ, Goodfellow E, Wenner J, Fleetham J, Ryan $\mathrm{CF}$, et al. The impact of a telemedicine monitoring system on positive airway pressure adherence in patients with obstructive sleep apnea: a randomized controlled trial. Sleep 2012;35(4):477-481.

27. Sparrow D, Aloia M, Demolles DA, Gottlieb DJ. A telemedicine intervention to improve adherence to continuous positive airway pressure: a randomised controlled trial. Thorax 2010;65(12):1061-1066.

28. Fields BG, Behari PP, McCloskey S, True G, Richardson D, Thomasson A, et al. Remote ambulatory management of veterans with obstructive sleep apnea. Sleep 2016;39(3):501-509.

29. Isetta V, León C, Torres M, Embid C, Roca J, Navajas D, et al. Telemedicine-based approach for obstructive sleep apnea management: building evidence. Interact J Med Res 2014;3(1):e6. 


\section{PAP Follow-Up Preferences Among Veterans}

30. Stepnowsky CJ, Palau JJ, Marler MR, Gifford AL. Pilot randomized trial of the effect of wireless telemonitoring on compliance and treatment efficacy in obstructive sleep apnea. J Med Internet Res 2007; 9(2):e14.

31. Hill RD, Luptak MK, Rupper RW, Bair B, Peterson C, Dailey N, Hicken BL. Review of Veterans Health Administration telemedicine interventions. Am J Manag Care 2010;16(12 Suppl HIT):e302-e310.

32. Barnwell SV, Juretic MA, Hoerster KD, Van de Plasch R, Felker BL. VA Puget Sound Telemental Health Service to rural veterans: a growing program. Psychol Serv 2012;9(2):209-211.

33. Hsueh MT, Eastman K, McFarland LV, Raugi GJ, Reiber GE. Teledermatology patient satisfaction in the Pacific Northwest. Telemed J E Health 2012;18(5):377-381.

34. Shore P, Goranson A, Ward MF, Lu MW. Meeting veterans where they're @: a VA Home-Based Telemental Health (HBTMH) pilot program. Int J Psychiatry Med 2014;48(1):5-17.

35. Luptak M, Dailey N, Juretic M, Rupper R, Hill RD, Hicken BL, Bair BD. The Care Coordination Home Telehealth (CCHT) rural demonstration project: a symptom-based approach for serving older veterans in remote geographical settings. Rural Remote Health 2010;10(2):1375.

36. Munafo D, Hevener W, Crocker M, Willes L, Sridasome S, Muhsin M. A telehealth program for CPAP adherence reduces labor and yields similar adherence and efficacy when compared to standard of care. Sleep Breath 2016;20(2):777-785.
37. Stepnowsky C, Edwards C, Zamora T, Barker R, Agha Z. Patient perspective on use of an interactive website for sleep apnea. Int $\mathrm{J}$ Telemed Appl 2013;2013:239382.

38. Agha Z, Lofgren RP, VanRuiswyk JV, Layde PM. Are patients at Veterans Affairs medical centers sicker? A comparative analysis of health status and medical resource use. Arch Intern Med 2000; 160(21):3252-3257.

39. United States Department of Veterans Affairs Office of Rural Health. Office of Rural Health Annual Report: Thrive 2015. http://www. ruralhealth.va.gov/docs/ORH_Annual_Report_2015_FINAL.pdf. Accessed September 13, 2016.

40. Veterans Affairs Northwest Health Network. VISN 20 Annual Report 2014. http://www.visn20.med.va.gov/VISN20/AnnualReports/ 2014VISN20AnnualReport.pdf. Accessed September 13, 2016.

41. Kelly JM, Schwamm LH, Bianchi MT. Sleep telemedicine: a survey study of patient preferences. ISRN Neurol 2012;2012:135329.

42. Hirshkowitz M, Sharafkhaneh A. A telemedicine program for diagnosis and management of sleep-disordered breathing: the fast-track for sleep apnea tele-sleep program. Semin Respir Crit Care Med 2014;35(5):560-570.

43. Schwab RJ, Badr SM, Epstein LJ, Gay PC, Gozal D, Kohler M, et al. An official American Thoracic Society statement: continuous positive airway pressure adherence tracking systems: the optimal monitoring strategies and outcome measures in adults. Am J Respir Crit Care Med 2013;188(5):613-620. 